\title{
Fate and Distribution Modelling of Metals in Life Cycle Impact Assessment
}

\author{
Strandesen, Maria; Birkved, Morten; Holm, Peter B.; Hauschild, Michael Zwicky
}

Published in:

Ecological Modelling

Link to article, DOI:

10.1016/j.ecolmodel.2006.12.013

Publication date:

2007

Link back to DTU Orbit

Citation $(A P A)$ :

Strandesen, M., Birkved, M., Holm, P. B., \& Hauschild, M. Z. (2007). Fate and Distribution Modelling of Metals in Life Cycle Impact Assessment. Ecological Modelling, 203, 327-338.

https://doi.org/10.1016/j.ecolmodel.2006.12.013

\section{General rights}

Copyright and moral rights for the publications made accessible in the public portal are retained by the authors and/or other copyright owners and it is a condition of accessing publications that users recognise and abide by the legal requirements associated with these rights.

- Users may download and print one copy of any publication from the public portal for the purpose of private study or research.

- You may not further distribute the material or use it for any profit-making activity or commercial gain

- You may freely distribute the URL identifying the publication in the public portal 


\title{
Fate and distribution modelling of metals in life cycle impact assessment
}

\author{
M. Strandesen ${ }^{a}$, M. Birkued ${ }^{b}$, P.E. Holm ${ }^{c}$, M.Z. Hauschild ${ }^{d, *}$ \\ a FORCE Technology, DK/2800 Lyngby, Denmark \\ b DHI Water and Environment, Agern Alle 5, DK-2970 Hørsholm, Denmark \\ c Department of Natural Sciences, The Royal Veterinary and Agricultural University of Denmark, DK-1871 Frederiksberg, Denmark \\ d Department of Manufacturing Engineering and Management, Technical University of Denmark, DK-2800 Lyngby, Denmark
}

\section{A R T I C L E I N F O}

Article history:

Received 28 September 2004

Received in revised form

29 November 2006

Accepted 6 December 2006

\section{Keywords:}

Fate modelling

Metals

Speciation

LCIA

Multiple species

Single species

\begin{abstract}
A B S T R A C T
Environmental risk assessment (ERA) and life cycle impact assessment (LCIA) models developed for the assessment of one form of non-ionic organic compounds, here termed species, have gained wide acceptance and use in assessments of chemicals in both ERA and LCIA (single-species approach). However, the aqueous chemistry of metal ions is very different from that of non-ionic organic compounds, since metals speciate into multi-species according to ambient aqueous and geochemical conditions as $\mathrm{pH}$ and availability of complexing agents (e.g. dissolved organic matter (DOM), chloride, carbonate). This study demonstrates a new modelling concept being able to perform both single-species assessment (SSA) and multi-species assessment (MSA). By applying multi-species fate modelling, the model has been shown able to account for a change in mobility of metals through coupled regions, caused by complexes formed with ligands such as DOM. It is concluded that single-species models should not be used to characterize the potential ecotoxicological impacts of metals in LCIA. Applying multi-species assessment methods strongly influences the availability of the most bioavailable form-the free metal ion, but it also makes the fate and exposure modelling of metals significantly more dependent on ambient conditions reflecting the very different speciation pattern and behaviour of metals at different sites.
\end{abstract}

(c) 2006 Elsevier B.V. All rights reserved.

\section{Introduction}

Estimation of chemical impacts in the environment using environmental risk assessment (ERA) and life cycle impact assessment (LCIA) typically relies on fate and exposure models which were developed for non-ionic hydrophobic organic compounds behaving as single species. Before applying such models to the assessment of (heavy) metals like cadmium (Cd), copper $(\mathrm{Cu})$, nickel $(\mathrm{Ni})$, lead $(\mathrm{Pb})$, and zinc $(\mathrm{Zn})$, it is important to realise that the behaviour and environmental fate of metals differs from that of organic compounds in several aspects, the most important of which are: (i) metals speciate, (ii) the speciation pattern of metals is influenced by the overall ambient biogeochemical conditions, (iii) the bioavailability of most metal species is not solely controlled by hydrophobic interactions, and (iv) metals are non-degradable elements.

Metal speciation reactions cause metals released to the aquatic compartments to undergo both abiotic and biotic transformation reactions and thereby form new inorganic and organic compounds or species containing the metal ions released. The metal may be released as one species, which then undergoes transformation processes forming new

\footnotetext{
* Corresponding author. Tel.: +45 45254664.

E-mail address: mic@ipl.dtu.dk (M.Z. Hauschild). 0304-3800/\$ - see front matter @ 2006 Elsevier B.V. All rights reserved. doi:10.1016/j.ecolmodel.2006.12.013
} 
chemical compounds. Typically, the transformation does not result in a single new compound, but in several new species of the metal, all showing properties which are different from those of the emitted metal species. The most striking consequence of this is that the form of the metal, which causes the strongest environmental impacts, is not necessarily the form in which the metal is originally released. In traditional singlespecies fate and exposure models, chemical compounds are modelled as the form in which they are released. Once this primary compound has been transformed to something else, the model considers the transformation product lost for the evaluative environment, and the impacts which are caused by the transformation products are thus typically not accounted for.

Metal speciation is controlled by the overall biogeochemical characteristics of the compartments, such as $\mathrm{pH}$, redox potential and presence of other cations and anions that may form complexes and precipitates with the metal ion of interest. The biogeochemical behaviour of each metal is unique meaning that the fraction of an emission which is present as a certain species differs among metals. Metals can therefore not be considered to behave according to a general pattern, as is assumed for organic chemical compounds in traditional single-species fate and exposure modelling. A fair representation of the environmental fate of metals requires a much more individual treatment.

The bioavailability of metals depends on the presence of complexing ligands (such as organic matter, inorganic ions, etc.) while bioavailability of organic compounds in fate and exposure models generally is considered to be limited only by the sorption onto large organic molecules and hydrophobic solid phases which reduces the exposure and the potential uptake in aquatic organisms. The substance's octanol-water partitioning coefficient, the $K_{\text {ow }}$ value, which is generally applied to predict the affinity of an organic chemical towards a hydrophobic phase, is not applicable for the quantification of the sorptive properties and the bioaccumulation potential of metals, since metals are sorbed and bioaccumulated by different mechanisms and not by lipophilic interactions. Instead, the uptake of metals by living organisms is controlled by the forms in which they are present (i.e. the actual speciation pattern), which again is controlled by the polar and ionic properties of the metal under influence of the conditions of the surrounding environment $(\mathrm{pH}$, redox potential, organic carbon content, etc.). The presence of dissolved organic matter (DOM), for instance, significantly influences the concentration of the bioavailable metal species. Furthermore, the uptake and bioaccumulation of some metals is influenced by the existence of active uptake mechanisms into the exposed organism, enabling it to accumulate essential metals to concentrations high above the concentrations of the media it is exposed to.

Taking stock of the state of the art for fate and exposure modelling of metals in ERA, a fate and exposure model is developed for the characterisation of aquatic ecotoxicological impacts caused by metals and metal species to be used in life cycle impacct assessment (LCIA). The use in LCIA poses some specific restrictions on the model (see Hauschild, 2005), including the necessity to operate with limited data on substances and environmental conditions. This being said, many of the findings are, however, also valid for fate modelling of metals in ERA.

\subsection{State of the art assessment of metals in ERA}

Environmental risk assessment (ERA) typically focuses on a single stage in the life cycle of the chemical compound or product, normally the use stage. The risks are characterised in ERA by application of various fate and exposure models, which enable the estimation of environmental exposure concentrations resulting from a given emission of the chemical. The predicted exposure concentrations can be compared to known effect concentrations for the chemical.

The development of aquatic metal exposure models and the advances in metal ecotoxicity over the last 30 years have increased the ability to predict the metal ecotoxicity in aquatic systems under very different conditions and with a good level of precision. The models developed are, e.g. the Gill surface interaction model (GSIM) (Pagenkopf, 1983), Windermere humic-aqueous model (WHAM) (Tipping, 1994), and finally the biotic ligand model (BLM) (as presented by Paquin et al., 2002). The development of these models has been more or less consecutive, so that the organism-water interactions model (GSIM) and speciation model (WHAM) both form the methodological foundation of the overall model, the BLM (see Fig. 1). In the BLM, WHAM models the aqueous chemistry, in which the speciation of the metal is determined, and GSIM models the processes governing the organism-water interface, which determines how much of the metal is taken up by an organism. At the moment, the BLM represents the state of the art within fate and exposure modelling of metals in ERA.

The high precision provided by the BLM comes at the expense of data requirements which limit its usability. One limitation concerns the number of metals for which the model at the moment is applicable ( $\mathrm{Cu}, \mathrm{Ag}, \mathrm{Cd}$ and $\mathrm{Zn}$; Niyogi and Wood, 2004). Another limitation is that the (biological) speciesspecific metal species interactions (see Fig. 1) are only provided for a few crustacean and fish species (standard test species) which means that the results in reality are representative for the exposure in a given site unless these standard organisms are considered representative for the species of the true target ecosystems.

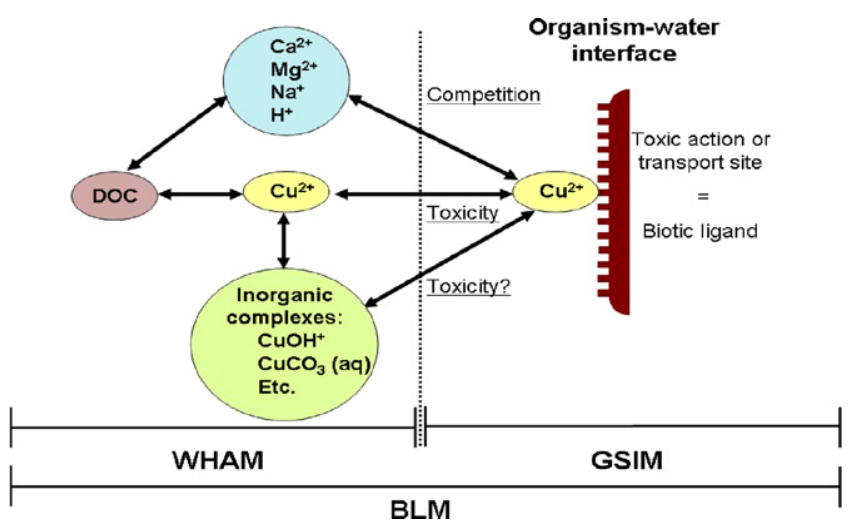

Fig. 1 - Conceptual relation between Gill surface interaction model (GSIM), Windermere humic-aqueous model (WHAM) and biotic ligand model (BLM). Based on Janssen et al. (2003). 


\subsection{State of the art assessment of metals in LCIA}

In contrast to ERA, life cycle assessment (LCA) assesses the environmental impacts caused by a product (or service) applying a life cycle perspective, i.e. including all activities associated with the product from the extraction of the needed raw materials over production and use of the product to its disposal and recycling. An inventory analysis is performed collecting data on input and output from all these processes related typically to one product unit. The emissions in an LCA are thus determined as the product's proportional share of the full emission from each process in its life cycle. They are generally determined from mass balances over each process and presented as emission mass loads (kg emitted per product), unaccompanied by information about the temporal course of the emission or the resulting concentrations in the receiving environment. Life cycle impact assessment (LCIA) thus has to operate on mass loads representing a share (often infinitesimal) of the full emission output from the processes within the additional restriction that the emissions of a given substance are aggregated for the entire product system over time and space, and that for many processes the knowledge about the geographical location is very limited.

LCIA is the phase in life cycle assessment where the flows of material associated with the product system are translated into consumptions of resources and, more relevant here, impacts on the environment. In principle the assessment includes any impact from the product's life cycle which can be expected to damage aspects of the environment ranging from local land use to global climate change. This means that LCIA addresses not only the toxic impacts (as ERA does) but also the other impacts associated with emissions of air pollutants (global warming, stratospheric ozone depletion, acidification, photochemical ozone and smog formation) or waterborne discharges (eutrophication and oxygen depletion), as well as the environmental impacts from different forms of land use, from noise and from radiation, and the use and loss of renewable and non-renewable resources. In order to avoid an unwanted bias in its treatment of the different environmental impacts, LCIA aims for best estimates in the applied modelling in contrast to the conservative approach, which is often taken in the early tiers of ERA (Hauschild, 2005).

Quantification of the environmental impacts from an emission applies characterisation factors (CFs) which are simply multiplied by the emitted quantity. The CFs can be regarded as the substance- and compartment-specific standard (linear) incremental contribution to a certain impact category (e.g. ecotoxicity) caused by a given compartment-specific discharge. Characterisation factors representing a substance's aquatic ecotoxicological impact are normally modelled as a sort of risk characterisation ratio, i.e. proportional to the aquatic predicted environmental concentration (PEC) and inversely proportional to some aquatic ecotoxicity effect measure (typically $\mathrm{HC}_{50}$ or PNEC; Pennington et al., 2004).

The holistic approach applied in LCA in terms of covering the whole product system and addressing all relevant environmental impacts is one of the strengths of LCA but it does not come without a cost. The vast number of processes, emission sites and chemicals typically included in the product system, and the modelling of many different environmental impacts does not allow for high data quality demands, like those typically encountered in ERA. Data of such quality can normally not be provided in LCA, and this means that application of fate and exposure models of a high precision, as that normally expected in ERA, is not feasible in LCIA for the estimation of potential toxicological impacts caused by emission of chemical compounds.

Some of the most frequently used characterisation models are USES-LCA (Huijbregts et al., 2000), which applies a SimpleBox core fate and exposure model (Brandes et al., 1996), CalTOX (Maddalena et al., 1995), which applies a Mackay level III core (Mackay, 2001), and EDIP (Wenzel et al., 1997), which applies a key property approach. All three apply a singlespecies assessment (SSA) approach typically focusing on the most likely free ion $\left(\mathrm{Cu}^{2+}, \mathrm{Cr}^{3+}\right.$, etc.), and they are hence not able to account for the behaviour of metals under varying ambient conditions of the aquatic recipients (Huijbregts et al., 2000). The inherent assumption in all these models is that the dissolved fraction of the metal in aquatic environments consists exclusively of the commonly regarded toxic species (the free metal ion). This assumption will normally lead to an overestimation of the potential toxic impact of a metal emission. The characterisation factors for metals are therefore often unrealistically high compared to the characterisation factors for organic substances, which is unfortunate given the comparative nature of LCIA. This was the background for the Apeldoorn expert workshop organised in 2004 under the UNEP/SETAC Life Cycle Initiative to discuss current problems in LCIA characterisation modelling for metals. In the declaration from the workshop, the participating experts identified a number of specific characteristics of metals which called for a different treatment in the calculation of characterisation factors. A core characteristic identified at the workshop was the fact that metals speciate and that the speciation pattern depends on different environmental settings (UNEP, 2004).

Diamond has proposed to address the effect of speciation on bioavailability of the metals in a manageable way through a pseudo-single-species assessment (PSSA) where weighted average values of the physical-chemical and fate properties of the species which are present are assigned to a pseudo species for which the fate and exposure characteristics is then modelled using an SSA approach (Diamond, 1999). This approach suffers from the inability to reflect the dynamics of the speciation pattern as function of changes in environmental parameters going from one part of the aquatic environment to another. MacLeod and co-workers suggested to solve this problem by using a multi-pseudo-single-species approach, basing the inter- and intra-species pool distribution on concentration ratios between the different species, but this solution limits the use of their approach to sites which have been investigated thoroughly (MacLeod et al., 2005).

To solve a complicated assessment issue like metal fate and exposure in a way which is applicable in LCIA, simplifications have to be made, and the model-user interface must be optimized to meet the requirements of the assessors in LCIA, who are typically non-experts in environmental chemistry. In the current situation, the lack of simplified multi-species models for metals, dedicated to this purpose, the LCIA practitioners are left with little choice but to apply models which were developed for single-species organic chemicals. 
ERA models exist, which are able to account for several species of an organic chemical emission, but as ERA and LCIA operate under very different data availability and data quality conditions, recently developed multi-species fate and exposure models (Cahill et al., 2003; Fenner et al., 2002) and other spatially resolved single-species models (Feijtel et al., 1998) developed within ERA are not easily applicable in LCIA due to their high data demand, and it seems unlikely that these can be adopted to assess the fate of metals, based solely on first order kinetics.

\section{Model development}

To meet the need for a fate model for metals, which respects metal speciation and its dependence on environmental conditions, which change with the location, a new metal fate model was developed. The model must cater to the characteristics of LCA, which means operate on mass flows, based on limited geographical information and knowledge about the ambient conditions of the product system, and aimed at comparisons between substances. Finally, the model must be applicable by LCA practitioners. The developed model is a regionally coupled multi-media model for metals (RCMM), which includes three coupled regions. Within each region a single-species model is simultaneously modelling each of the five dominating individual chemical species of the metal, typically accounting for $90-100 \%$ of the total metal present in any of the modelled compartments. The inclusion of more species is possible, but requires data about their specific properties, notably their species-specific $K_{d}$ value.

The pattern of distribution between the species is determined from a geochemical database containing concentration ratios between the chemical species of the metal. The RCMM database contains the speciation patterns of the metals $\mathrm{Cu}$, $\mathrm{Pb}, \mathrm{Zn}, \mathrm{Ni}$ and $\mathrm{Cd}$ under varying environmental conditions and is linked with a fate and distribution model to account for the speciation and species parameterisation through a set of three linked regions in such a way that the different speciation patterns within each region are easily modelled (see Fig. 2).

The metal speciation database was created by the use of Visual MINTEQ (KTH, 2003), which is based on the MINTEQA2 code (Allison et al., 1991), and the fate and distribution model is similar to a Mackay level II model (Mackay, 2001). Each region in the linked fate and distribution model is assigned a specific water composition in terms of its salinity, $\mathrm{pH}$ and dissolved organic carbon (DOC) content. From this composition, the metal speciation pattern is determined and retrieved from the metal speciation database (see Fig. 2). The region-specific

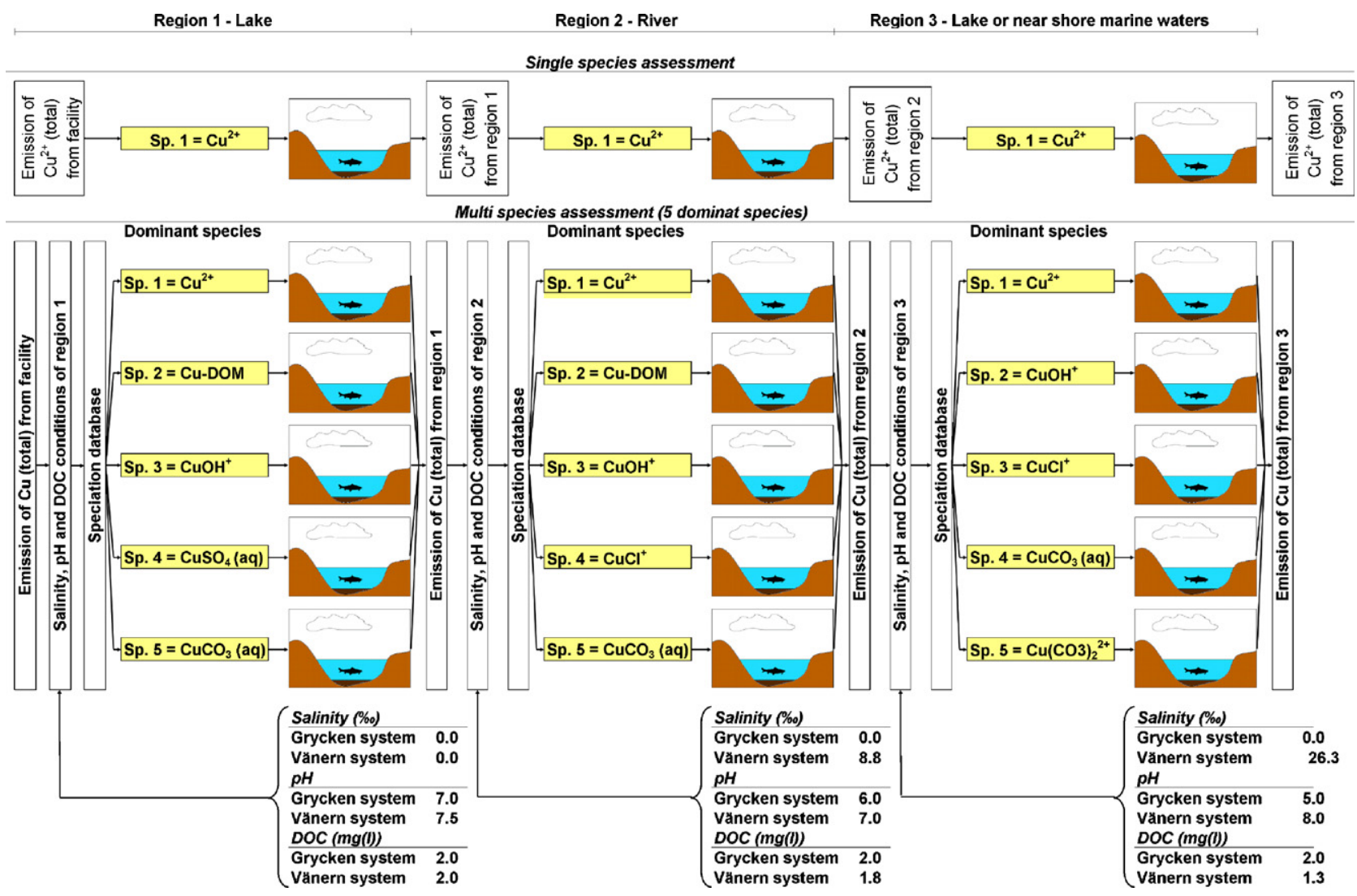

Fig. 2 - Regionally coupled single-species assessment (SSA) (top part of the figure) and regionally coupled multi-species assessment (MSA) (lower part of the figure) of copper. Single-species assessment modelling only considers the free metal ion, whereas the multi-species model works on "mirrored unit worlds" within each region enabling the assessment of multiple species (here the five dominant species within each region). Presented dominant species are valid for the Lake Vänern system. 
speciation pattern within each region is independent of the speciation pattern of the adjacent regions.

Since the speciation pattern within each region is modelled based on static species-specific concentration ratios and not dynamically, and since the speciation pattern within each region is independent of the adjacent regions, the approach is termed "decoupled" multi-species modelling.

The metal speciation database and the different water chemistry scenarios applied in the model are described in more detail in the Supporting information.

\subsection{The fate and distribution core model}

The Mackay level II steady-state equilibrium model (as described in Mackay, 2001) was chosen as the core model in the RCMM due to its fairly small data-requirements, its reasonably simple algebra and good transparency, and its acceptable environmental realism. In case of dynamic non-steady-state behaviour, a Mackay level III (Mackay, 2001) model would give more accurate predictions, but as mentioned earlier, emissions in LCA are reported as mass flows and the temporal discharge pattern is rarely known. Furthermore, a level III model requires input data such as inter-media transport coefficients (better known as $D$ values), which can not realistically be provided in a sufficient quality for all of the many different types of geographical locations which can be encountered in LCIA, considering its global scope. A number of existing fate and distribution models were considered as candidates for the core model (ChemCAN, Woodfine et al., 2001; CalTOX, Maddalena et al., 1995; USES-LCA, Huijbregts, 1999), but these are all based on level III models or methodological clones hereof and hence not suitable for the purpose of implementing region coupling and accounting for multi-species of metals within LCIA.

The chosen core model is thus a steady-state equilibrium model with flow, which includes loss of chemical by advection and reaction. The base model contains six compartments (air, water, soil, sediment, suspended sediment and fish) and is mode of entry unspecific. For further details regarding the calculation principles and methodologies within the chosen model please refer to Mackay (2001).

\subsection{Estimation of metal species-specific $K_{d}$ values}

Partitioning of metal ions between solid and solution phases controls the distribution and bioavailability of a given metal and can be characterised by the distribution coefficient $K_{d}$ $(\mathrm{L} / \mathrm{kg})$, which is the metal concentration in the solid phase divided by the metal concentration in the solution phase at equilibrium. In this study, the equilibrium partitioning was estimated based on empirically determined relationships between $\mathrm{pH}$ and $\log \mathrm{K}_{\mathrm{d}}$ of divalent metal ions. Several adsorption studies of metal ions in soils and sediment have documented that $\mathrm{pH}$ is the parameter contributing most significantly to explain the variation in $K_{d}$ values, and the linear models presented by Sauvé et al. (2000) include relationships between $\mathrm{pH}$ and $\mathrm{K}_{\mathrm{d}}$ for the five metals $\mathrm{Cd}, \mathrm{Cu}, \mathrm{Ni}$, $\mathrm{Pb}$, and $\mathrm{Zn}$. These relationships were used for the five metals included in the RCMM (see Table B of the Supporting information). Similar well-documented $\mathrm{pH}-\log \mathrm{K}_{\mathrm{d}}$ correlations are currently not available for other metals in the literature. Given the crucial role played by the sorption of metals, these five metals are therefore the only metals which the RCMM at present can cover. For future inclusion of other metals in the RCMM, species-specific sorption data must be provided for these, e.g. using multi-elemental analytical techniques.

Metal species and complexes of the five divalent metals with zero or negative charge are assigned a $K_{d}$ value of $0 \mathrm{~L} / \mathrm{kg}$ due the poor charge-dependent affinity of compounds which are neutral or negatively charged to the negatively charged binding sites on the soil and sediment particles, expected to dominate the sorbing phases of importance and assuming that the complexation of sorbent and sorbate is governed by columbic (charge dependent) interactions and exchange. Only metal species and complexes with a positive charge are predicted to adsorb and they are all assigned the $\mathrm{pH}$-dependent $K_{d}$ values estimated by the expressions suggested by Sauvé et al. (2000).

The metal ion complexes with DOM are assigned a $K_{d}$ value of $1 \mathrm{~L} / \mathrm{kg}$ on the basis of two studies on sorption of DOM to soils by Shen (1999) and Kaiser and Guggenberger (2000). $\mathrm{K}_{\mathrm{d}}$ $\mathrm{DOM}$ is the $K_{d}$ value of DOM, i.e. the ratio between the amount of adsorbed DOM (to soil) and the amount of dissolved DOM. Shen (1999) finds that $K_{d}$-DOM varies from 0 to $21 \mathrm{~L} / \mathrm{kg}$ for an EH soil. The soil types investigated by Shen (1999) and Kaiser and Guggenberger (2000) are considered comparable to the default soil in the RCMM. Following Lee and Kuo (1999) it is assumed in the RCMM that metal bound DOM exhibits the same partitioning behaviour as unbound DOM, and hence, that the $K_{d}$ value for metal-DOM complexes is equal to the $K_{d}$ value for DOM. Furthermore, the $K_{d}-D O M$ values determined for adsorption of DOM to soil are assumed to represent the adsorption of DOM to sediment and suspended sediment in the RCMM.

\subsection{Species-specific bioaccumulation potential}

Within the framework of the RCMM it is necessary to define bioconcentration factors (BCFs) for each metal species within each region. The target organisms with respect to bioconcentration of metal species in the RCMM are here assumed to be two different fish species. At present no species-specific BCF values for metals are available in the literature, thus BCFs based on total metal concentrations from USEPA (2002) were chosen.

Since freshwater as well as seawater is inhabited by different species of fish, two BCF values were found for each metal-one representing fish species in marine waters and one representing fish species in freshwater. The BCF chosen represented the tests performed with the longest duration. BCF values for the brackish waters were calculated as average values for the chosen metal species in fresh- and marine waters. The metal-DOM complexes were assigned a BCF value of zero, based on the studies by respectively Landrum et al. (1987) and McCarthy (1989) presented in Haitzer et al. (1999). These studies indicate that DOM complexes are too large to be taken up by organisms and therefore, a bioaccumulation of metal-DOM complexes is not expected to occur. 


\subsection{Regional coupling}

Only a limited number of existing environmental fate and distribution models attempt to account for spatial differentiation of the fate and exposure of chemicals. The models attempting to do so, typically link their fate and distribution model core to a geographic information system (GIS), which then provides the necessary region-specific hydrological and meteorological data. In the setup of the RCMM to model the Swedish lake Vänern and Lake Grycken systems, which are used in Section 3 to demonstrate the use of the model, the necessary flow data were retrieved from statistic sources (Lindgren and Pantzare, 2001; Vänerns Vattenvårdsförbund, 2002).

Since both modelled lake systems include three regions, the general procedure of accounting for spatial differentiation in the RCMM involved creation of three identical copies of the RCMM-base model for which the water and suspended sediment compartments were linked via static averaged advective flow data. Advective loss by the air compartment was not included in the model since none of the five metals had species with significant vapour pressures. Handling of advective losses by the air compartment could however easily be included, if relevant, and would only require quantification of the advective air flow between the individual regions.

The number of linked regions can easily be expanded from three to any desired number.

\subsection{Region-specific speciation patterns}

A basic assumption applied in the RCMM is, that a metal emitted to a region quantitatively reaches the water compartment, where it speciates instantaneously according to the pattern defined by the specific environmental conditions of that region. Within each region the individual species sorbs and is buried or stays dissolved as the metal ion or soluble species hereof. When the metal species are transferred by advection to the adjacent region, they instantaneously speciate according to a new pattern, determined by the ambient aquatic conditions in the new region. Since the model core used here was based on chemical equilibrium, the specific pattern of metal species within each region is assumed constant once the composition of the water is fixed. There is thus no dynamic mass exchange between the species within each region.

\subsection{Model input}

Based on the water chemistry parameters of a region ( $\mathrm{pH}$, salinity and DOC content-see Table A of Supporting information), the RCMM retrieves the relevant metal speciation pattern from the metal speciation database and calculates the distribution of each metal species in that region. Thus the only parameters which the user needs to define, in order to retrieve the metal speciation pattern in each region, are the salinity, $\mathrm{pH}$, and DOC concentration, the metal of interest and the amount of metal released to the emission region. Furthermore, the user has the option of using static or $\mathrm{pH}$ dependent $K_{d}$ values. The static $K_{d}$ values included in the database originate from the extensive literature review performed by Ambrose (1999).
In order for the RCMM model to calculate the distribution of the metal species in each region, the user furthermore needs to specify the regions in terms of volume $\left(\mathrm{m}^{3}\right)$, residence time (h), and density $\left(\mathrm{kg} / \mathrm{m}^{3}\right)$ of respectively water, air, soil, sediment, suspended sediment and fish. Also the organic content of soil, sediment and suspended sediment, and the water temperature must be specified for each region. Finally, the specific advective water flows $\left(\mathrm{m}^{3} / \mathrm{h}\right)$ between the regions have to be specified to complete the characterisation of the water system.

Since all significant metal species are either ions or complexes hereoff, all metal species included in the RCMM are assigned a hypothetical low vapour pressure of $1 \times 10^{-11} \mathrm{~Pa}$ (as presented by Mackay et al., 1996), due to the fact that none of these species distributes significantly into the atmospheric compartment. However, there are metalloid and metal species which are volatile (e.g. species of arsenic (As) and mercury $(\mathrm{Hg})$ ), and these should be ascribed their accurate vapour pressures when included in the model, which should then also be extended with advection in the air compartment.

Since metals are non-degradable elements, all metal species are assigned a hypothetical high degradation half-life value of $1 \times 10^{12} \mathrm{~h}$ based on the value set for $\mathrm{Pb}$ as presented in Mackay et al. (1996). For the bioavailable metal molecules, this half-life should be interpreted as the average time they remain bioavailable after emission.

\section{Comparison of the metal assessment in the two Swedish lake systems using single- and multi-species assessment}

In order to illustrate the difference in the assessment of a metal using a single-species assessment (SSA) approach and a multi-species assessment (MSA) approach, two site-specific SSAs and two site-specific MSAs of metals are performed using the RCMM on two Swedish lake systems (the Lake Vänern system and the Lake Grycken system). Both lake systems are part of large fresh water systems and mainly discharge water to downstream rivers. Both systems consist of three connected regions, a lake, a downstream river and a downstream lake or estuary. The river which receives water from Lake Grycken discharges into Lake Varpan, and the river receiving water from Lake Vänern discharges into the marine waters of Kattegat. Another important difference of the two systems is the size of their main lake. Lake Vänern is one of the largest fresh water bodies in Sweden, while lake Grycken is a small lake. The main characteristics of the two lake systems are presented in Table $\mathrm{C}$ of the Supporting information.

Effluents from paper mills located at Lake Vänern and Lake Grycken in Sweden are known to contain $\mathrm{Cu}, \mathrm{Ni}, \mathrm{Zn}$ and $\mathrm{Pb}$. To quantify the site dependency of the environmental impact from such metal emissions, the Predicted Environmental Concentrations, PECs, in the aquatic compartments in each region of the two lake systems, resulting from a theoretical emission rate of $1 \mathrm{~kg} / \mathrm{h}$ in their upstream region, were calculated using the SSA and the MSA approaches.

To assess the ecotoxicity of metals in an MSA approach, it is important to know which species contribute to the ecotoxicity. It is generally acknowledged (Paquin et al., 2002) that the total metal concentration correlates poorly with metal 
ecotoxicity. According to Paquin et al. (2000), the metal ecotoxicity is generally related directly to the concentration of the free metal ion and accordingly, it is assumed that the only species contributing to the ecotoxicity is the free metal ion $\left(\mathrm{M}^{2+}\right)^{1}$

\subsection{Species factor}

The ratio of the PECs of the free metal ion, which are calculated using the SSA and MSA, is determined to analyse the influence of taking speciation into account:

$\mathrm{SPF}_{\mathrm{f}}=\frac{\mathrm{PEC}_{\mathrm{f}, \mathrm{M}^{2+}, \mathrm{MSA}}}{\mathrm{PEC}_{\mathrm{f}, \mathrm{M}^{2+}, \mathrm{SSA}}}$

where $\mathrm{SPF}_{\mathrm{f}}$ (unit less) is the species factor for compartment ' $\mathrm{f}$ ' of the modelled system, $\mathrm{PEC}_{\mathrm{f}, \mathrm{M}^{2+}, \mathrm{MSA}}\left(\mathrm{g} / \mathrm{m}^{3}\right)$ the predicted environmental concentration of the free metal ion in compartment ' $\mathrm{f}$ ' obtained by the MSA approach, and $\mathrm{PEC}_{\mathrm{f}, \mathrm{M}^{2+}, \mathrm{SSA}}$ $\left(\mathrm{g} / \mathrm{m}^{3}\right)$ is the predicted environmental concentration of the free metal ion in compartment ' $\mathrm{f}$ ' obtained using the SSA approach.

\subsection{Site factor}

Characterisation models in LCIA are traditionally based on standard model environments, and to investigate the significance of performing a site-specific characterisation of the metal's fate in the aquatic compartment, the predicted environmental concentrations are compared region by region for the two lake systems. The site factor is calculated as the ratio of aquatic exposure concentrations within each of the regions:

$\mathrm{SF}_{\mathrm{MSA}, \text { region } x, \mathrm{M}}=\frac{\mathrm{PEC}_{\mathrm{MSA}, \text { region } x(\text { Vänern system }), \mathrm{M}^{2+}}}{\mathrm{PEC}_{\mathrm{MSA}, \text { region } x(\text { Grycken system }), \mathrm{M}^{2+}}}$

where $\mathrm{SF}_{\mathrm{MSA} \text {,region } x, \mathrm{M}}$ is the site factor for region $\mathrm{x}$ (first, second or third region) and the free ion of metal $M$ in the aquatic compartment by the MSA approach,

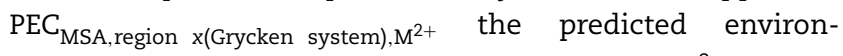
mental concentration of the free metal ion $\left(\mathrm{M}^{2+}\right)$ in the aquatic compartment in region $x$ of the Lake Grycken system, calculated according to the MSA approach, and

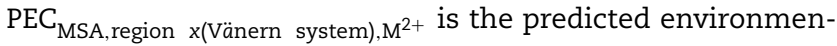
tal concentration of $\mathrm{M}^{2+}$ in the aquatic compartment in region $x$ of the Lake Vänern system, calculated according to the MSA approach.

$\mathrm{SF}_{\mathrm{SSA}, \text { region } x, \mathrm{M}}=\frac{\mathrm{PEC}_{\mathrm{SSA}, \text { region } x(\text { Vänern system }), \mathrm{M}^{2+}}}{\mathrm{PEC}_{\mathrm{SSA}, \text { region } x(\text { Grycken system }), \mathrm{M}^{2+}}}$

\footnotetext{
${ }^{1}$ This assumption leads to a mismatch if the PEC is compared with ecotoxicological effect measures (like PNEC or $\mathrm{HC}_{50}$ ) which are expressed as total metal concentrations. The problem can be solved for the results of standard tests, where the composition of the aquatic test media is known, making it possible to estimate the metal speciation pattern in the test media and thereby account for the percentage of metal present as the free metal ion in the standard tests.
}

Table 1 - Steady-state PECs ( $\mu \mathrm{g} / \mathrm{L}$ ) of copper in the Lake Grycken- and the Lake Vänern system modelled by running the RCMM in single-species mode (SSA) and multi-species mode (emission of copper to region 1 is $1 \mathrm{~kg} / \mathrm{h})$

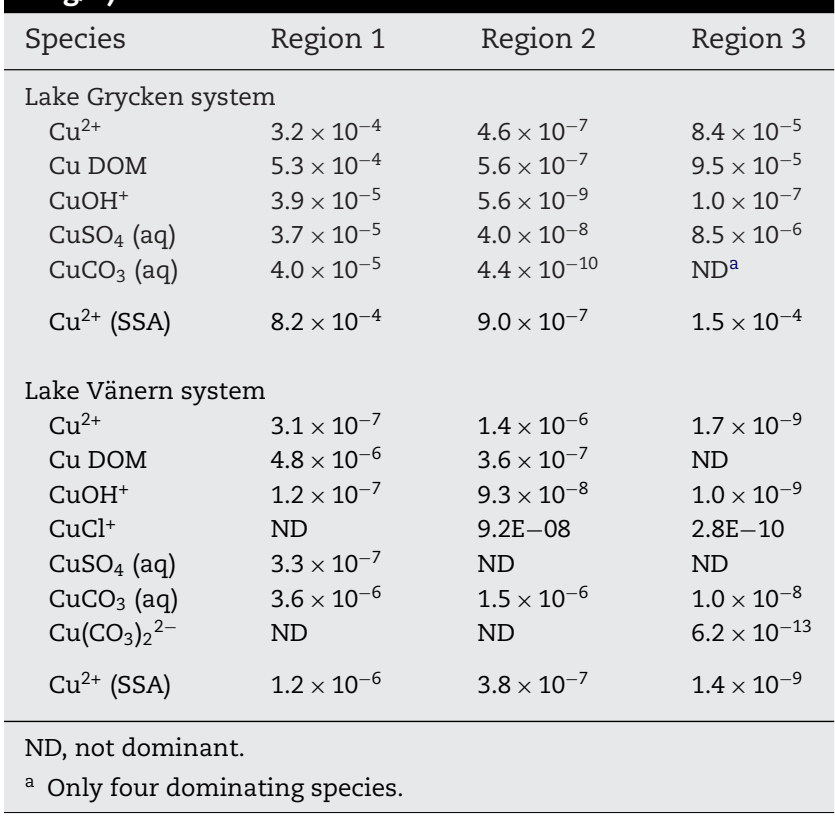

where $\mathrm{SF}_{\mathrm{SSA} \text {,region } x, \mathrm{M}}$ is the site factor for region $\mathrm{x}$ (first, second or third region) and the free ion of metal $M$ in the aquatic compartment by the SSA approach,

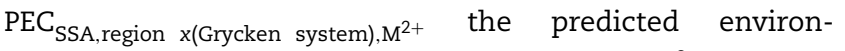
mental concentration of the metal ion $\left(\mathrm{M}^{2+}\right)$ in the aquatic compartment in region $x$ of the Lake Grycken system, calculated according to the SSA approach, and

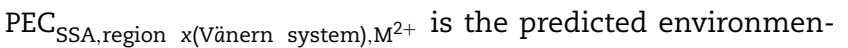
tal concentration of $\mathrm{M}^{2+}$ in the aquatic compartment in region $x$ of the Lake Vänern system, calculated according to the SSA approach.

\section{Results from applying the RCMM on the two systems}

The PECs resulting from running the RCMM model in MSA and SSA mode are presented for copper for both lake systems in Table 1 ( PEC $_{\mathrm{MSA}}$ and $\mathrm{PEC}_{\mathrm{SSA}}$ ). Similar calculations were performed for $\mathrm{Cu}, \mathrm{Ni}, \mathrm{Zn}$ and $\mathrm{Pb}$ (data not shown). The singlespecies assessments were carried out using the RCMM with only one possible species for each metal, the free metal ion $\left(\mathrm{M}^{2+}\right)$, within each region.

\subsection{Comparison of single and multi-species assessment of four metals}

The species factors (SPFs) for the individual metals were calculated at steady state for each region according to Eq. (1). The results of the assessment methods comparison are presented in Fig. 3. It is seen that for the Lake Grycken system, multispecies assessment tends to give lower PEC values for the free ion (resulting in an SPF below 1) in all regions compared to 

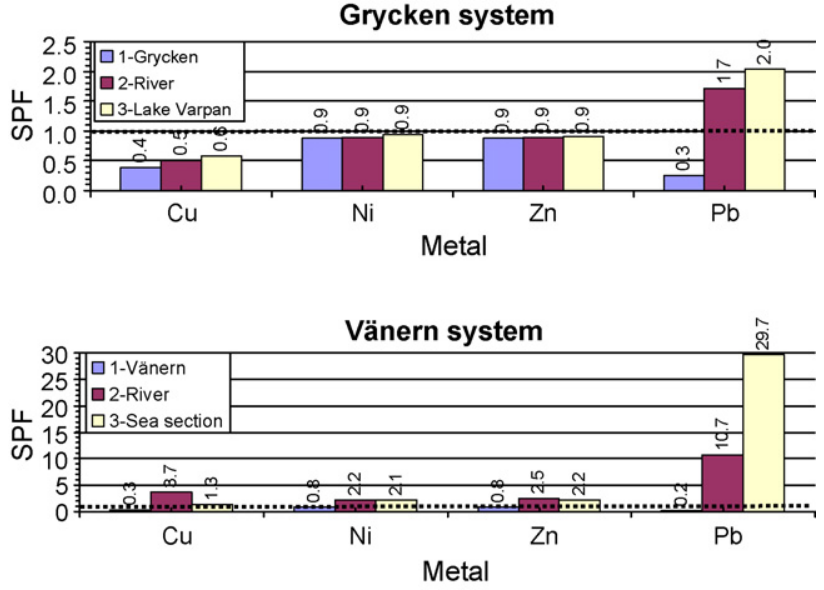

Fig. 3 - SPFs of the free metal ions $\left(\mathrm{M}^{2+}\right)$ of $\mathrm{Cu}, \mathrm{Ni}, \mathrm{Zn}$ and $\mathrm{Pb}$ by emission of $1 \mathrm{~kg} / \mathrm{h}$ to either Lake Grycken or Lake Vänern. SPF is calculated according to Eq. (1).

the single-species assessment, except for the metal lead in the two downstream regions. For the Lake Vänern system the predicted free ion concentration becomes lower in region 1 but higher in regions 2 and 3 for all modelled metals when MSA is applied.

\subsection{Site-specific comparison of single- and} multi-species assessment of four metals

The influence of the water chemistry on the speciation pattern and thereby the exposure concentration of the free metal ion in the two lake systems is compared by calculating the SFs of the free metal ion in all three regions according to Eqs. (2) and (3). The resulting PECs and SFs are presented in Table 2. Apart from one case, the SF is higher than one implying that the predicted free metal ion concentration is higher in all three

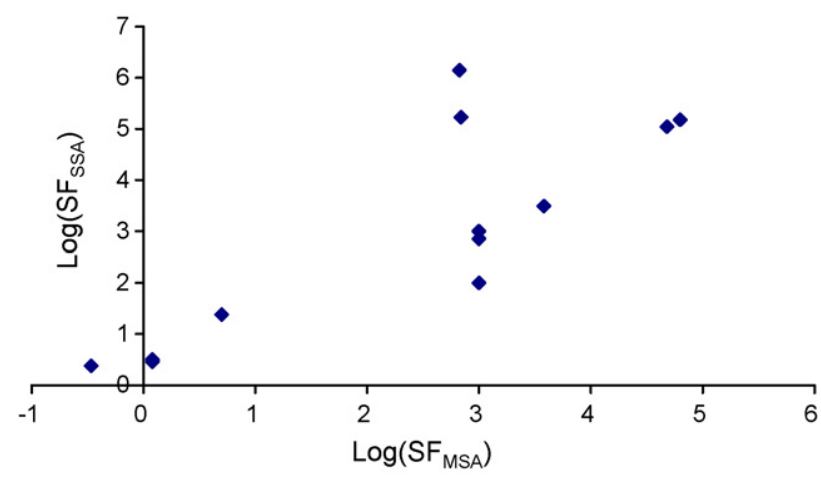

Fig. 4 - Plot of the site factors presented in Table 2 obtained by the MSA and SSA for the four metals included in the case study.

regions of the Lake Vänern system than in the similar regions of the Lake Grycken system.

The ratios between the two systems, however vary several orders of magnitude, and in order to help interpret the relation between the $\mathrm{SF}_{\mathrm{MSA}}$ and $\mathrm{SF}_{\mathrm{SSA}}$, the two types of site factors are plotted against each other in Fig. 4. The figure shows no apparent relationship between the site factors achieved using MSA and SSA.

\section{Sensitivity analysis}

A sensitivity analysis of the environmental parameters in the RCMM was carried out in order to identify the parameters with the highest influence on the aquatic PEC of the free metal ion. The sensitivity analysis was carried out by changing selected environmental parameters in region 1 and monitoring the resulting aquatic $\mathrm{PEC}$ values for the free metal ion in all three regions. The sensitivity of each parameter was studied separately. The salinity, DOM content and $\mathrm{pH}$ were changed by

Table 2 - PECs and associated SFs (see Eqs. (2) and (3)) for the free metal ion of $\mathrm{Cu}, \mathrm{Pb}, \mathrm{Zn}$ and Ni calculated for the three regions of the Lake Vänern system and the Lake Grycken system using MSA and SSA, assuming an emission of the free metal ion of $1 \mathrm{~kg} / \mathrm{h}$ to region 1

\begin{tabular}{|c|c|c|c|c|c|c|c|}
\hline \multirow[t]{3}{*}{ Metal } & \multirow[t]{3}{*}{ Region } & \multicolumn{4}{|c|}{$\mathrm{PEC}_{\mathrm{RCMM}, \mathrm{M}^{2+}}(\mu \mathrm{g} / \mathrm{L})$} & \multirow[t]{3}{*}{$\mathrm{SF}_{\mathrm{MSA}}$} & \multirow[t]{3}{*}{$\mathrm{SF}_{\mathrm{SSA}}$} \\
\hline & & \multicolumn{2}{|c|}{ Lake Grycken system } & \multicolumn{2}{|c|}{ Lake Vänern system } & & \\
\hline & & MSA & SSA & MSA & SSA & & \\
\hline \multirow{3}{*}{$\mathrm{Cu}$} & 1 & $2.0 \times 10^{-2}$ & $7.3 \times 10^{-2}$ & $2.0 \times 10^{1}$ & $5.2 \times 10^{1}$ & $1.0 \times 10^{3}$ & $7.1 \times 10^{2}$ \\
\hline & 2 & $8.8 \times 10^{-2}$ & $2.4 \times 10^{-2}$ & $3.0 \times 10^{-2}$ & $5.7 \times 10^{-2}$ & $3.4 \times 10^{-1}$ & $2.4 \times 10^{0}$ \\
\hline & 3 & $1.1 \times 10^{-4}$ & $8.9 \times 10^{-5}$ & $5.3 \times 10^{0}$ & $9.4 \times 10^{0}$ & $4.8 \times 10^{4}$ & $1.1 \times 10^{5}$ \\
\hline \multirow[t]{3}{*}{$\mathrm{Zn}$} & 1 & $4.3 \times 10^{-2}$ & $5.1 \times 10^{-2}$ & $4.5 \times 10^{1}$ & $5.3 \times 10^{0}$ & $1.0 \times 10^{3}$ & $1.0 \times 10^{2}$ \\
\hline & 2 & $4.5 \times 10^{-2}$ & $1.8 \times 10^{-2}$ & $5.2 \times 10^{-2}$ & $5.8 \times 10^{-2}$ & $1.2 \times 10^{0}$ & $3.2 \times 10^{0}$ \\
\hline & 3 & $1.4 \times 10^{-2}$ & $6.5 \times 10^{-5}$ & $9.7 \times 10^{0}$ & $1.1 \times 10^{1}$ & $6.9 \times 10^{2}$ & $1.7 \times 10^{5}$ \\
\hline \multirow[t]{3}{*}{$\mathrm{Pb}$} & 1 & $5.0 \times 10^{-4}$ & $2.4 \times 10^{-3}$ & $1.9 \times 10^{0}$ & $7.4 \times 10^{0}$ & $3.8 \times 10^{3}$ & $3.1 \times 10^{3}$ \\
\hline & 2 & $4.0 \times 10^{-3}$ & $3.7 \times 10^{-4}$ & $1.5 \times 10^{-2}$ & $8.8 \times 10^{-3}$ & $5.0 \times 10^{0}$ & $2.4 \times 10^{1}$ \\
\hline & 3 & $1.5 \times 10^{-5}$ & $4.9 \times 10^{-7}$ & $0.1 \times 10^{-1}$ & $6.8 \times 10^{-1}$ & $6.7 \times 10^{2}$ & $1.4 \times 10^{6}$ \\
\hline \multirow[t]{3}{*}{$\mathrm{Ni}$} & 1 & $4.5 \times 10^{-2}$ & $5.5 \times 10^{-2}$ & $4.7 \times 10^{1}$ & $5.5 \times 10^{1}$ & $1.0 \times 10^{3}$ & $1.0 \times 10^{3}$ \\
\hline & 2 & $4.6 \times 10^{-2}$ & $2.1 \times 10^{-2}$ & $5.4 \times 10^{-2}$ & $6.0 \times 10^{-2}$ & $1.2 \times 10^{0}$ & $2.9 \times 10^{0}$ \\
\hline & 3 & $1.6 \times 10^{-4}$ & $7.5 \times 10^{-5}$ & $1.0 \times 10^{1}$ & $1.1 \times 10^{1}$ & $6.3 \times 10^{4}$ & $1.5 \times 10^{5}$ \\
\hline
\end{tabular}


Table 3 - Sensitivity analysis results for $\mathrm{Cu}, \mathrm{Ni}, \mathrm{Pb}$ and $\mathrm{Zn}$

\begin{tabular}{|c|c|c|c|c|c|c|c|c|c|c|}
\hline \multirow[t]{2}{*}{ Metal } & \multirow[t]{2}{*}{ Region } & \multicolumn{9}{|c|}{ Sensitivity ratios (SR) } \\
\hline & & Salinity & DOM & $\mathrm{pH}$ & $\begin{array}{l}\text { Vol. } \\
\text { water }\end{array}$ & $\begin{array}{c}\text { Vol. } \\
\text { sediment }\end{array}$ & $\begin{array}{l}\text { Vol. suspended } \\
\text { sediment }\end{array}$ & $\begin{array}{l}\text { Res. } \\
\text { water }\end{array}$ & $\begin{array}{c}\text { Res. } \\
\text { sediment }\end{array}$ & $\begin{array}{l}\text { Res. suspended } \\
\text { sediment }\end{array}$ \\
\hline \multirow[t]{3}{*}{$\mathrm{Cu}$} & 1 & 0.07 & -0.49 & -10.41 & -0.08 & -0.34 & -0.02 & 0.06 & 0.31 & 0.01 \\
\hline & 2 & -0.05 & 0.34 & 3.71 & -0.63 & -0.02 & 0.01 & 0.94 & 0.02 & -0.01 \\
\hline & 3 & -0.05 & 0.34 & 3.71 & -0.63 & -0.02 & 0.01 & 0.94 & 0.02 & -0.01 \\
\hline \multirow[t]{3}{*}{$\mathrm{Ni}$} & 1 & 0.00 & 0.03 & -8.38 & -0.06 & -0.34 & -0.02 & 0.04 & 0.32 & 0.01 \\
\hline & 2 & 0.04 & -0.28 & -1.27 & -0.27 & -0.22 & 0.14 & 0.37 & 0.21 & -0.09 \\
\hline & 3 & 0.04 & -0.28 & -1.27 & -0.27 & -0.22 & 0.14 & 0.37 & 0.21 & -0.09 \\
\hline \multirow[t]{3}{*}{$\mathrm{Pb}$} & 1 & -0.20 & 1.39 & -10.18 & 0.00 & -0.36 & -0.02 & 0.00 & 0.35 & 0.01 \\
\hline & 2 & -0.11 & 0.79 & 8.41 & -0.64 & -0.01 & 0.03 & 0.96 & 0.01 & -0.02 \\
\hline & 3 & -0.11 & 0.79 & 8.41 & -0.64 & -0.01 & 0.03 & 0.96 & 0.01 & -0.02 \\
\hline \multirow[t]{3}{*}{$\mathrm{Zn}$} & 1 & -0.05 & 0.37 & -7.89 & -0.06 & -0.35 & -0.02 & 0.04 & 0.32 & 0.01 \\
\hline & 2 & -0.05 & 0.34 & 5.04 & -0.24 & -0.24 & 0.16 & 0.34 & 0.22 & -0.11 \\
\hline & 3 & -0.05 & 0.34 & 5.04 & -0.24 & -0.24 & 0.16 & 0.34 & 0.22 & -0.11 \\
\hline
\end{tabular}

Vol., volume; Res., residence time. The sensitivity ratio (see Eq. (4)) is given for the nine most influential parameters in controlling the PEC of the free metal ion in the water phase. A negative sensitivity ratio indicates that input and output are inversely related, i.e. increasing the input value decreases the output value.

1 unit, whereas the values for the other environmental parameters were changed by $50 \%$.

The sensitivity ratios $\mathrm{SR}_{\mathrm{X}}$ of the individual parameters were calculated as the incremental change (in percentage) for the model output divided by the incremental change (in percentage) for the model input:

$\mathrm{SR}_{\mathrm{X}}=\frac{\left(\mathrm{PEC}_{\mathrm{M}^{2+}, \text { end }}-\mathrm{PEC}_{\mathrm{M}^{2+}, \text { start }}\right) / \mathrm{PEC}_{\mathrm{M}^{2+}, \text { start }}}{\left(\mathrm{X}_{\text {end }}-\mathrm{X}_{\text {start }}\right) / \mathrm{X}_{\text {start }}}$

where $\mathrm{PEC}_{\mathrm{M}^{2+}, \text { start }}$ is the initial aquatic predicted environmental concentration of the free metal ion, $\mathrm{PEC}_{\mathrm{M}^{2+}}$,end the aquatic predicted environmental concentration of the free metal ion after increasing parameter $X, X_{\text {start }}$ the initial value of the parameter and $X_{\text {end }}$ is the final value of the parameter.

The results of the sensitivity analysis are presented in Table 3.

As seen from the sensitivity ratios in Table $3, \mathrm{pH}$ is the single water chemistry parameter which shows the strongest influence on the PECs of the free ions of all the four metals in all regions. DOM is also influential while salinity only shows a minor influence on the free metal ion concentration. Physical parameters like compartment residence times and compartment volumes also exhibit moderate influence on the PECs, comparable to DOM but weaker than the $\mathrm{pH}$ parameter.

\section{Discussion}

The RCMM has been developed to account for the site-specific differences in the increase in exposure concentration of bioavailable metal in the aquatic recipients, following an emission, taking into account the speciation of the metal. Applying multiple copies of the same model within each model region, as illustrated in Fig. 2, is a fairly simple approach to account for the complex chemistry of metals in aquatic recipients. The approach used here is static steady state catering to the conditions of LCIA, where the data availability is generally low, and the typical assessor does not posses the specific chemistry skills needed to apply and run highly sophisticated environmental chemical models. No matter which approach is used, modelling multiple species will require species-specific data. Species-specific data for parameters like $K_{d}$ are still not found for individual metal species, and correct parameterisation of the individual species will most likely not be possible in the near future. Using common sense and available research results, it has been the aim to parameterise the model in a credible way.

The main assumptions and limitations of the model are listed in Table 4.

RCMM models the change in concentration of different metal species following an emission in the first upstream region of the system. It has not been possible to find monitoring data for any of the modelled systems which would allow validation of the model against empirical data. It has also not been possible to find any other model against which the RCMM results can be validated in any meaningful way. Traditional ERA models do not support the combination of metal speciation and spatial differentiation with multiple regions which is the main feature of the RCMM model. The characterisation models applied in LCIA also do not support validation due to their site generic nature and the single-species framework they all have been cast from. It is however a general problem for characterisation models as applied in LCIA, that they do not lend themselves easily to validation against empirical data. The aim of these models (of which the RCMM model is one) is to model incremental concentration additions from a given unit process (see Hauschild, 2005) and not total loads. This feature makes validation by comparison to empirical data a theoretical possibility only.

The PECs for $\mathrm{Cu}$ obtained by applying SSA and MSA are shown in Table 1. The results indicate that even for metals that 
Table 4 - List of the main assumptions and limitations of the RCMM model

Main assumptions in the RCMM model

Steady state, equilibrium

Metal-DOM complexes assigned a BCF value of 0 and $K_{d}$ value of 1 (equal to $K_{d}$ value for DOM)

No volatilisation of metal species

Metal species or complexes with a zero or negative charge are assigned a $K_{d}$ value of zero (complexations of sorbent and sorbate assumed governed by columbic (charge dependent) interactions and exchange)

Main limitations in the RCMM model

No dynamic/time-dependency, only handles continuous emissions (thus catering to the conditions of LCA where the temporal course of an emission is rarely known)

Only models five most dominating species of each metal

Only three linked regions (but easy to expand)

Only five metals modelled (but more can be included depending on availability of species-specific data)

speciate in such a way that the dominant species is the free metal ion, the choice of applying the MSA or SSA does result in significant differences in the concentration of bioavailable metal, most pronounced in the Lake Vänern system. For a metal like $\mathrm{Pb}$, for which the dominant ion is not the free metal ion, the differences become more pronounced as shown in Fig. 3.

For both types of metal behaviour, the assessment method significantly affects the resulting exposure concentration of the bioavailable metal. For the region of emission (region 1 in both lake systems) the application of the MSA approach results in a decrease of $10-80 \%$ in the predicted concentration of the free metal ion and hence in the aquatic ecotoxicological potential, compared to the SSA approach. In the emission region of both lake systems the single-species assessment method thus tends to estimate a higher concentration of bioavailable metal than the multi-species assessment. The largest difference is observed for $\mathrm{Pb}$ in both lake systems. This should be seen in the perspective that the traditional modelling approach typically only applies one model region. As seen in Table 1, the DOM-associated fraction of $\mathrm{Cu}$ is among the largest singlespecies fraction in all regions, and the inclusion of DOM in the modelling thus significantly lowers the bioavailability of copper. A similar reduction in the bioavailable fraction in region 1 is observed in Fig. 3 for the other metals, and also here, DOM complexes play an important role (data not shown).

For the second region, which is a river section in both systems, the differences in the water chemistry tend to give a more differentiated picture. In the river of the Lake Grycken system, the picture is similar to what was observed for region 1 except for $\mathrm{Pb}$ where the application of the MSA approach results in higher exposure concentration of the free metal ion. In the Lake Vänern system, on the other hand, the application of the MSA approach results in higher exposure concentrations of the free metal ion for all four metals.

For the third region in the two lake systems, the difference between the water chemistry becomes larger, since one is a lake (in the Lake Grycken system) and one is an estuary, and the ratio in bioavailable metal concentrations obtained by the two assessment approaches peaks at a factor 30. In the third region of both systems, the largest differences between the two assessment methods are observed for $\mathrm{Pb}$. The large differences found for lead are caused by the formation of nonsorbing anionic $\mathrm{Pb}$ species or lead complexes with DOM in the first and second region, which increases the mobility of the metal, resulting in a stronger transport downstream. This leads to exposure concentrations in regions downstream from the region of emission, which clearly exceed the exposure concentrations found downstream when speciation is disregarded.

When applying the SSA approach or the MSA approach, the influence of the different ambient conditions in the two lake systems are expressed in the PEC of the free metal ion as presented in Table 2. The magnitude of the differences between the two sites, when modelling the same emission, $1 \mathrm{~kg} / \mathrm{h}$, applying either of the method does not seem to follow an easily predictable pattern as presented in Fig. 4, since the PECs modelled by both methods can not be considered to be correlated.

The main factors controlling the exposure concentration in the SSA approach are sorption and dilution of the only species assessed, the free metal ion, whereas in the MSA approach, speciation is allowed to influence the fate behaviour of the metal. Consideration of the different physical chemical and fate properties of the individual species in the MSA approach leads to results which do not lend themselves to any straightforward interpretation of the relation between the exposure concentrations of the free metal ion modelled by the two approaches as presented in Fig. 4.

In spite of the fact that the emission rate is fixed at $1 \mathrm{~kg} / \mathrm{h}$ for both systems, the calculated exposure concentrations of the regions of the lake Grycken and the lake Vänern systems for the four metals vary by four orders of magnitude for the MSA approach and six orders of magnitude for the SSA as seen from Table 2. The magnitude of the SF obtained by the two modelling approaches indicates that for both approaches, the same emission will cause impacts of very different magnitude depending on where in the lake system the emission occurs, even if both emissions occur within the same country. The comparison of the two modelling approaches indicates that single-species assessment possibly overestimates this difference between the individual model regions, as the SFs and thereby the site dependency of the SSA approach is one to two orders of magnitude higher than that of the MSA approach.

As presented in Table 3, the application of the MSA approach in combination with $\mathrm{pH}$-dependent $\mathrm{K}_{\mathrm{d}}$ values does result in a high model sensitivity towards $\mathrm{pH}$. This sensitivity is most likely caused by alterations in speciation patterns and alteration of the metal affinity towards the sorbent.

Applying MSA instead of SSA results in a $\mathrm{pH}$-dependent exposure concentration, which is in good line with the results 
on aquatic ecotoxicity relations to $\mathrm{pH}$ presented by Paquin et al. (2002).

\section{Conclusion}

The decoupled MSA and the traditional SSA approach result in different exposure concentrations of the bioavailable metal form, the free metal ion, mainly because the multiple species approach takes into consideration, that not all of the metal from a metal emission will be present as the free metal ion. By applying multi-species fate modelling and including mobile sorbents in the species pool, the model has been shown able to account for a change in mobility of metals, caused by sorption to dissolved mobile ligands such as DOM.

In the first region all metals have a lower bioavailable exposure concentration when their speciation is taken into account, than when modelled as single species, i.e. the traditional single-species approach overestimates the toxicity of the metals. This picture changes with the water advection to adjacent regions, so that the metals in downstream regions under one set of ambient conditions show a lower exposure concentration for the free metal ion according to the MSA approach than to the SSA approach, and hence under different ambient conditions possess a higher ecotoxicity potential when modelled according to the MSA approach than when modelled according to the SSA approach.

Based on the results presented here it can be concluded that single-species models should not be used to characterize the potential ecotoxicological impacts of metals, since the behaviour of metals can not be generalized and grasped within a single-species model which assumes a fairly uniform behaviour of metals in very different model regions. The site dependent speciation pattern does not lend itself to generalisations in the same manner as for non-ionic organic chemical compounds, due to the complex biogeochemistry and behaviour of the individual metal species. Applying multispecies assessment methods makes the fate and exposure modelling of metals significantly more dependent on ambient conditions reflecting the very different speciation pattern and behaviour of metals at different sites, and hence increases the need for spatially differentiated fate and exposure modelling.

\section{Appendix A. Supplementary data}

Supplementary data associated with this article can be found, in the online version, at doi:10.1016/j.ecolmodel.2006.12.013.

\section{REFERE N C E S}

Allison, J.D., Brown, D.S., Novo-Gradac, K.J., 1991.

Minteqa2/Prodefa2, A Geochemical Assessment Model for Environmental Systems: Version 23.0 User's Manual.

Environmental Research Laboratory Office of Research and Development, U.S. Environmental Protection Agency, Athens, Georgia 30605. EPA/600/3-91/021 March, 1991.

Ambrose Jr., R.B., 1999. Partition Coefficients for Metals in Surface Water, Soil and Waste (Draft). U.S. Environmental Protection
Agency Office of Solid Waste, Washington, DC 20460, June 22, 1999.

Brandes, L.J., den Hollander, H., van de Meent, D., 1996. SimpleBox 2.0: A Nested Multimedia Fate Model for Evaluating the Environmental Fate of Chemicals. Report No. 719101029. National Institute of Public Health and the Environment (RIVM), P.O. Box 1, 3720 BA Bilthoven, The Netherlands.

Cahill, T.M., Cousins, I., MacKay, D., 2003. General fugacity-based model to predict the environmental fate of multiple chemical species. Environ. Toxicol. Chem. 22 (3), 483-493.

Diamond, M.L., 1999. Development of a fugacity/aquivalence model of mercury dynamics in lakes. Water, Air, Soil Pollut. 111, 337-357.

Feijtel, T., Boeije, G., Matthies, M., Young, A., Morris, G., Gandolfi, C., Hansen, B., Fox, K., Matthijs, E., Koch, V., Schroder, R., Cassani, G., Schowanek, D., Rosenblom, J., Holt, M., 1998. Development of a geography-referenced regional exposure assessment tool for European rivers-GREAT-er. J. Hazard. Mater. 61, 59-65.

Fenner, K., Kooijman, C., Scheringer, M., Hungerbühler, K., 2002. Including transformation products into the risk assessment for chemicals: the case of nonylphenol ethoxylate usage in Switzerland. Environ. Sci. Technol. 36, 1147-1154.

Haitzer, M., Höss, S., Traunspurger, W., Steinberg, C., 1999. Relationship between concentration of dissolved organic matter (DOM) and the effect of DOM on the bioconcentration of benzo[a]pyrene. Aquat. Toxicol. 45, 147-158.

Hauschild, M., 2005. Assessing environmental impacts in a life cycle perspective. Environ. Sci. Technol. 39 (4), 81A-88A.

Huijbregts, M.A.J., 1999. Priority Assessment of Toxic Substances in the Frame of LCA. Development and Application of the Multi-Media Fate, Exposure and Effect Model USES-LCA. Interfaculty Department of Environmental Science, Faculty of Environmental Sciences, University of Amsterdam, Holland.

Huijbregts, M.A.J., Thissen, U., Guinée, J.B., Jager, T., van de Meent, D., Ragas, Wegener, A., Sleeswijk, Reijnders, L., 2000. Priority assessment of toxic substances in life cycle assessment. I. Calculation of ecotoxicity potentials for 181 substances with the nested multi-media fate, exposure and effects model USES-LCA. Chemosphere 41, 541-573.

Janssen, C.R., Heijerick, D.G., De Schamphelaere, K.A.C., Allen, H.E., 2003. Environmental risk assessment of metals: tools for incorporating bioavailability. Environ. Int. 28, 793-800.

Kaiser, K., Guggenberger, G., 2000. The role of DOM sorption to mineral surfaces in the preservation of organic matter in soils. Org. Geochem. 31, 711-725.

KTH, 2003. Visual MINTEQ ver 2.21. Kungliga Tekniska Högskolan, Stockholm, Sweden.

Landrum, P.F., Nihart, S.R., Eadie, B.J., Herche, L.R., 1987. Reduction in bioavailability of organic contaminants to the amphipod Pnotoporeia hoyi by dissolved organic matter of sediment interstitial waters. Environ. Toxicol. Chem. 6, $11-20$.

Lee, C., Kuo, L., 1999. Quantification of the dissolved organic matter effect on the sorption of hydrophobic organic pollutant: application of an overall mechanistic sorption model. Chemosphere 38 (4), 807-821.

Lindgren, H., Pantzare, H., 2001. The Interface Between the Technical System. Grycksbo Paper Mill and the Environmental System, Lake Grycken. Examensarbete Miljöteknik No.: E 2319 Mi, Chalmers Tekniska Högskola, Gothemburg, Sweden.

Mackay, D., 2001. Multimedia Environmental Models, The Fugacity Approach, 2nd ed. Lewis Publishers, Boca Raton, Florida.

Mackay, D., Di Guardo, A., Paterson, S., Cowan, C.E., 1996. Evaluating the environmental fate of a variety of types of chemicals using the EQC model. Environ. Toxicol. Chem. 15 (9), 1627-1637. 
MacLeod, M., McKone, T.E., Hunt, J.R., Mackay, D., 2005. A mercury mass balance for the San Francisco Bay area: development and application of a regional multi-species fugacity model. Environ Sci. Technol. 39, 6721-6729.

Maddalena, R.L., McKone, T.E., Layton, D.W., Hsieh, D.P.H., 1995. Comparison of multi-media transport and transformation models: regional fugacity model vs. CalTOX. Chemosphere 30, 869-889.

McCarthy, J.F., 1989. Bioavailability and ecotoxicity of metals and hydrophobic organic contaminants. In: Suffet, I.H., NacCarthy, P. (Eds.), Aquatic Humic Substances. Influence on Fate and Treatment of Pollutants. Washington, DC. American Chemical Society, pp. 263-277.

Niyogi, S., Wood, C.M., 2004. Biotic ligand model, a flexible tool for developing site-specific water quality guidelines for metals. Environ. Sci. Technol. 38 (23), 6177-6192.

Pagenkopf, G.K., 1983. Gill surface interaction model for trace-metal ecotoxicity to fishes: role of complexation, $\mathrm{pH}$, and water hardness. Environ. Sci. Technol. 17, 342-347.

Paquin, P.R., Santore, R.C., Wu, K.B., Kavvadas, C.D., Di Toro, D.M., 2000. The biotic ligand model: a model of the acute ecotoxicity of metals to aquatic life. Environ. Sci. Policy 3, 175-182.

Paquin, P.R., Gorsuch, J.W., Apte, S., Batley, G.E., Bowles, K.C., Campbell, P.G.C., Delos, C.G., Di Toro, D.M., Dwyer, R.L., Galvez, F., Gensemer, R.W., Goss, G.G., Hogstrand, C., Janssen, C.R., McGeer, J.C., Naddy, R.B., Playle, R.C., Santore, R.C., Schneider, U., Stubblefield, W.A., Wood, C.M., Wu, K.B., 2002. The biotic ligand model: a historical overview. Comp. Biochem. Physiol. C 133, 3-35.

Pennington, D.W., Payet, J., Hauschild, M., 2004. Aquatic ecotoxicological indicators in life cycle assessment. Environ. Toxicol. Chem. 23 (7), 1796-1807.
Sauvé, S., Hendershot, W., Allen, H.E., 2000. Solid-solution partitioning of metals in contaminated soils: dependence on $\mathrm{pH}$, total metal burden and organic matter. Environ. Sci. Technol. 34 (7), 1125-1131.

Shen, 1999. Sorption of natural dissolved organic matter on soil. Chemosphere 38 (7), 1505-1515.

Tipping, E., 1994. WHAM-a chemical equilibrium model and computer code for waters, sediments, and soils incorporating a discrete site/electrostatic model of ion-binding by humic substances. Comput. Geosci. 20, 973-1023.

UNEP, 2004. Declaration of Apeldoorn on LCIA of Non-Ferro Metals. United Nations Environment Programme Division of Technology, Industry, and Economics. http://www.uneptie. org/pc/sustain/reports/lcini/Declaration\%20of\%20Apeldoorn final_2c.pdf.

USEPA, 2002. U.S. Environmental Protection Agency. User Guide: ECOTOXicology Database System. Version 3.0. Available from: http://www.epa.gov/ecotox/ (accessed January 2004).

Vänerns Vattenvårdsförbund, 2002. Vänern-Årsskrift 2002. Rapport no. 22. AB C O Ekblad \& Co., Västervik, Sweden.

Wenzel, H., Hauschild, M.Z., Alting, L., 1997. Environmental Assessment of Products. Methodology, Tools and Case Studies in Product Development, vol. 1. Chapman \& Hall/Kluwer Academic Publishers, United Kingdom/Hingham, MA, USA, ISBN 0412808005

Woodfine, D., MacLeod, M., Mackay, D., 2001. A Regionally Segmented National Scale Multimedia Contaminant Fate Model for Canada with GIS Data Input and Display. Canadian Environmental Modelling Centre, Environmental and Resource Studies Trent University Peterborough, Ontario, Canada K9J 7B8. 